\title{
Trend analysis of the 20-year time series of stratospheric ozone profiles observed by the GROMOS microwave radiometer at Bern
}

\author{
L. Moreira ${ }^{1}$, K. Hocke ${ }^{1}$, E. Eckert ${ }^{2}$, T. von Clarmann ${ }^{2}$, and N. Kämpfer ${ }^{1}$ \\ ${ }^{1}$ Institute of Applied Physics and Oeschger Centre for Climate Change Research, University of Bern, Bern, Switzerland \\ ${ }^{2}$ Karlsruhe Institute of Technology, Institute for Meteorology and Climate Research, Karlsruhe, Germany
}

Correspondence to: L. Moreira (lorena.moreira@iap.unibe.ch)

Received: 22 April 2015 - Published in Atmos. Chem. Phys. Discuss.: 17 June 2015

Revised: 21 September 2015 - Accepted: 21 September 2015 - Published: 5 October 2015

\begin{abstract}
The ozone radiometer GROMOS (GROund-based Millimeter-wave Ozone Spectrometer) has been performing continuous observations of stratospheric ozone profiles since 1994 above Bern, Switzerland (46.95 N, 7.44 E, $577 \mathrm{~m})$. GROMOS is part of the Network for the Detection of Atmospheric Composition Change (NDACC). From November 1994 to October 2011, the ozone line spectra were measured by a filter bench (FB). In July 2009, a fast Fourier transform spectrometer (FFTS) was added as a back end to GROMOS. The new FFTS and the original FB measured in parallel for over 2 years. The ozone profiles retrieved separately from the ozone line spectra of FB and FFTS agree within $5 \%$ at pressure levels from 30 to $0.5 \mathrm{hPa}$, from October 2009 to August 2011. A careful harmonisation of both time series has been carried out by taking the FFTS as the reference instrument for the FB. This enables us to assess the long-term trend derived from stratospheric ozone observations at Bern. The trend analysis was performed by using a robust multilinear parametric trend model which includes a linear term, the solar variability, the El Niño-Southern Oscillation (ENSO) index, the quasi-biennial oscillation (QBO), the annual and semi-annual oscillation and several harmonics with period lengths between 3 and 24 months. Over the last years, some experimental and modelling trend studies have shown that the stratospheric ozone trend is levelling off or even turning positive. With our observed ozone profiles, we are able to support this statement by reporting a statistically significant trend of $+3.14 \%$ decade $^{-1}$ at $4.36 \mathrm{hPa}(37.76 \mathrm{~km})$, covering the period from January 1997 to January 2015, above Bern.
\end{abstract}

Additionally, we have estimated a negative trend over this period of $-3.94 \% \mathrm{decade}^{-1}$ at $0.2 \mathrm{hPa}(59 \mathrm{~km})$.

\section{Introduction}

For many decades it has been known that the stratospheric ozone layer shields the Earth's surface from harmful solar ultraviolet radiation (UV), thus enabling life on Earth and protecting humans and the biosphere against adverse effects. Molina and Rowland (1974) were the first to propose that this protective layer could be depleted by anthropogenic emission of chlorofluorocarbons (CFCs) to the atmosphere. The photodecomposition of CFCs and other long-lived organic molecules in the stratosphere releases chlorine $(\mathrm{Cl})$ and bromine $(\mathrm{Br})$ atoms that destroy ozone molecules in catalytic cycles. In the last Scientific Assessment of Ozone Depletion: 2014 of the World Meteorological Organization (WMO, 2014) it is stated that global ozone levels decreased through the 1980s and early 1990s while stratospheric abundances of ozone-depleting substances (ODSs) were increasing.

In 1985, massive ozone losses in measured column abundances during the Antarctic spring were reported and heterogeneous chlorine chemistry on polar stratospheric clouds (PSCs) were implicated for the loss (WMO, 2011). Around that time and over the later years, the Montreal Protocol and its amendments and adjustments were enacted with the aim to reduce the production and consumption of ODSs. Actions taken under the Montreal Protocol have led to decreases 
in the atmospheric abundance of controlled ODSs and are enabling the return of the ozone layer toward 1980 levels (WMO, 2014).

From the late 1990s, there were some measurements and model calculations indicating a turnaround in the decreasing ozone, suggesting that the negative ozone trends in the stratosphere would level out or even become positive (Newchurch et al., 2003). Nevertheless, during this recovery phase, ozone levels will also be affected by the expected anthropogenic increases in abundances of other ozone-relevant gases (carbon dioxide $\left(\mathrm{CO}_{2}\right)$, methane $\left(\mathrm{CH}_{4}\right)$, and nitrous oxide $\left.\left(\mathrm{N}_{2} \mathrm{O}\right)\right)$ as well as by the natural influences of volcanic eruptions, solar activity, and the natural variability in the Earth's climate (WMO, 2014).

The concerns regarding anthropogenic depletion of stratospheric ozone increased the necessity for precise and accurate measurements to monitor long-term trends in this species. (Parrish et al., 1992). Passive millimetre-wave radiometry has been used to monitor the vertical distribution of atmospheric trace gases since the early 1970s (Palm et al., 2010). The need for continuous monitoring of the stratospheric response to anthropogenic trace gas releases, performed by a well-defined set of instruments, led to the foundation of the Network for the Detection of Stratospheric Change (NDSC) (now Network for the Detection of Atmospheric Composition Change - NDACC) in 1991. The ozone radiometer GROMOS (GROund-based Millimeterwave Ozone Spectrometer) is part of the NDACC; hence our more-than-20-year harmonised time series are available via http://ftp.cpc.ncep.noaa.gov/ndacc/station/bern/hdf/mwave/.

Ozone time series from the GROMOS microwave radiometer were used for comparisons with lidar, ozonesondes and collocated satellite observations, and for detection of long-term trends (Dumitru et al., 2006; Steinbrecht et al., 2006; Steinbrecht et al., 2009; Keckhut et al., 2010; van Gijsel et al., 2010; Studer et al., 2013; Delcloo and Kreher, 2013; WMO, 2014).

Ground-based millimetre-wave radiometry is a powerful technique for trace gas measurements due to its low sensitivity to weather conditions and aerosol contamination. Since ozone radiometers measure the thermal microwave emission of ozone in the middle atmosphere, they do not require external illumination sources, such as laser pulses or the solar irradiance. The measurements can therefore be made throughout day and night. Among other advantageous technical features, the more than 20 years of continuous observations and the privileged location of the instrument offer us a pretty clear vision of the distribution of ozone in the northern midlatitudes $\left(46.95^{\circ} \mathrm{N}, 7.44^{\circ} \mathrm{E}, 577 \mathrm{~m}\right)$.

We perform a trend study of our time series of stratospheric ozone profiles through a new robust multilinear parametric trend estimation method (von Clarmann et al., 2010). The program minimises a cost function in order to estimate the linear trend of a time series. The cost function consists of the quadratic norm of the residual between a regression model and the measured time series, weighted by the inverse covariance matrix of the data errors. Error correlations between data points are supported, making the program suitable for consideration of autocorrelated residuals. This generic trend method takes the entire effect of correlated residuals into account, but it does not correct them. The method is particularly useful when a time series is constructed of multiple data sets where different calibration standards and other errors with systematic components have to be considered. Further, this method takes into account autocorrelated residuals which are caused by atmospheric variability on timescales larger than the sampling distance of the data but not described properly by the multilinear trend model chosen. Since the related additional autocorrelated error term can change the weight of the data points, its inclusion does not only lead to a larger, more realistic, error estimate but can slightly change the trend estimate, too. The regression model consists of an axis intercept, a linear trend, sine waves, and several proxies. Unknown biases between data subsets are handled by assigning a fully correlated error term to each data point of one of the data subsets. With this trend analysis tool a complete treatment of the uncertainties is assured, making this trend analysis particularly valuable to confirm the aforementioned ozone turnaround with a representative station in central Europe. Trend studies of ozone profiles based on ground-based microwave measurements are rare. In fact, since Steinbrecht et al. (2006) we are not aware of any other publication; therefore, the purpose of this paper is to present a new trend estimation based on stratospheric ozone profiles measured by a ground-based microwave at northern midlatitudes $\left(46.95^{\circ} \mathrm{N}, 7.44^{\circ} \mathrm{E}, 577 \mathrm{~m}\right)$.

The present study is organised as follows: the description of the instrument, the measurement technique, the spectrometer upgrade and the retrieval method are presented in Sect. 2. Section 3 summarises the procedure carried out for the harmonisation of ozone profiles, followed by a detailed description of the trend estimation method in Sect. 4. Section 5 deals with the characterisation of GROMOS uncertainty sources. The estimated trend is presented in Sect. 6, concluding with an overview of our result in an overall context. And finally, Sect. 7 is a summary of our findings.

\section{The GROMOS radiometer}

GROMOS is an ozone radiometer, located at the University of Bern $\left(46.95^{\circ} \mathrm{N}, 7.44^{\circ} \mathrm{E}\right)$, Switzerland. It has been operating continuously since November 1994 in the framework of the NDACC.

\subsection{Measurement technique}

GROMOS is a $142 \mathrm{GHz}$ total power radiometer observing at an elevation angle of $40^{\circ}$ in the north-east direction. Alternatively, its plane mirror rotates to take measurements from a 


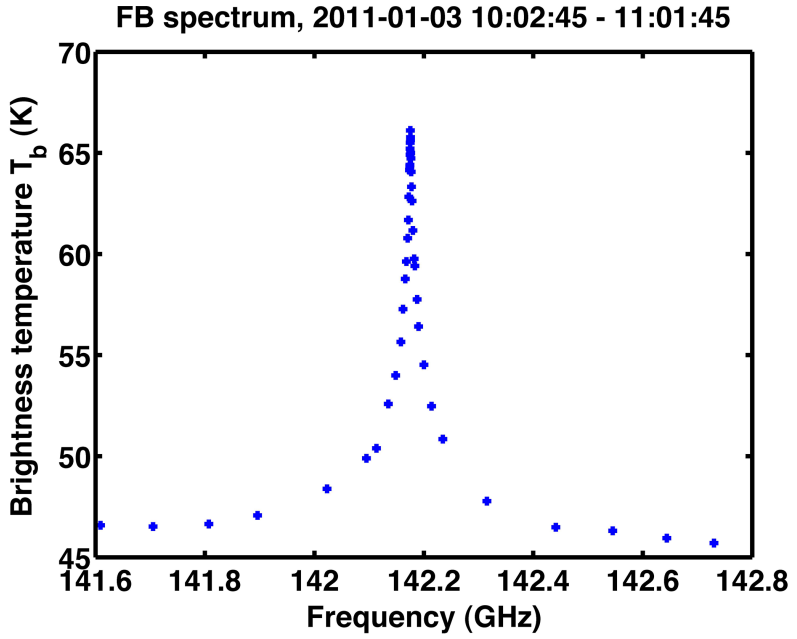

Figure 1. Measurement of the ozone spectrum line at $142 \mathrm{GHz}$ at Bern on a winter day with the filter bench spectrometer. The integration time is $60 \mathrm{~min}$.

hot black body (heated to $313 \mathrm{~K}$ ), the atmosphere (through a microwave transparent styrofoam window) and a cold black body (immersed in liquid nitrogen at $80 \mathrm{~K}$ ). The hot and cold load measurements are recorded for calibration purposes. The mirror switches position every $8 \mathrm{~s}$, enabling an accurate black body calibration of the ozone emission line. The detected radiation is led through a quasi-optics system, where a Martin-Puplett interferometer (MPI) works as a filter with destructive interference for the radiation at the upper sideband $(149.57504 \mathrm{GHz})$ and constructive interference at $142.17504 \mathrm{GHz}$. Then the signal is collected by a horn antenna and mixed with the $145.875 \mathrm{GHz}$ wave of a local oscillator for down conversion to an intermediate frequency of $3.7 \mathrm{GHz}$ prior to being analysed by a spectrometer.

\subsection{Spectrometer upgrade}

The spectral analysis was performed by a filter bench (FB) spectrometer from November 1994 to October 2011. The 45channel FB had a total bandwidth of $1.2 \mathrm{GHz}$, with individual filters with a frequency resolution varying from $200 \mathrm{kHz}$ at the line centre to $100 \mathrm{MHz}$ at the wings. Figure 1 shows as an example a calibrated spectrum recorded on a winter morning in 2011 by the FB spectrometer, with an integration time of $60 \mathrm{~min}$.

In July 2009, an Acqiris fast Fourier transform spectrometer (FFTS) was added as a back end to GROMOS. The FFTS covers a total bandwidth of $1 \mathrm{GHz}$ with 32768 channels, giving a frequency resolution of around $30.5 \mathrm{kHz}$. A sample of a calibrated ozone spectrum is given in Fig. 2. It shows the ozone line recorded by the FFTS on the same winter morning as the FB spectrum (Fig. 1). The integration time is $30 \mathrm{~min}$, and no frequency binning is applied in the blue
FFTS spectrum, 2011-01-03 10:15:00 - 10:44:55

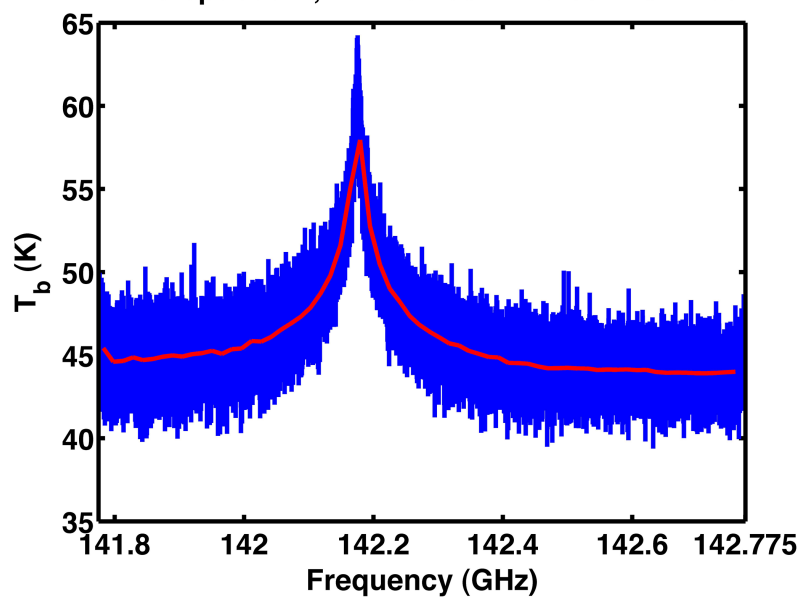

Figure 2. Ozone spectrum line at $142 \mathrm{GHz}$ recorded by the Acqiris FFT spectrometer at Bern on a winter day. The integration time is $30 \mathrm{~min}$. The red line represents the frequency binned.

Table 1. GROMOS instrument specifications.

\begin{tabular}{ll}
\hline Location & Bern, Switzerland \\
\hline & $46.95^{\circ} \mathrm{N}, 7.44^{\circ} \mathrm{E}, 577 \mathrm{~m}$ \\
Direction of view & North-east \\
Elevation angle & $40^{\circ}$ \\
Mode of operation & Total power \\
Mixer temperature & $294 \mathrm{~K}$ (uncooled, room temperature) \\
System noise temperature & $2520 \mathrm{~K}$ (single side band) \\
Frequency of ozone line & $142.17504 \mathrm{GHz}$ \\
Target species & $\mathrm{O}_{3}$ \\
Auxiliary quantities & Tropospheric opacity at 142 GHz \\
Altitude range retrieved & $25-70 \mathrm{~km}$ \\
Spectrometer & $45-\mathrm{channel} \mathrm{FB} \mathrm{(Nov} \mathrm{1994} \mathrm{to} \mathrm{Oct} \mathrm{2011)}$ \\
& $32768-\mathrm{channel}$ FFTS (since Jul 2009) \\
Total bandwidth & $1.2 \mathrm{GHz}(\mathrm{FB})$ \\
& $1 \mathrm{GHz}(\mathrm{FFTS})$ \\
Frequency resolution & $20 \mathrm{kHz}$ at line centre, 100 MHz \\
& at line wings (FB) \\
Time resolution for the & $30.5 \mathrm{kHz}(\mathrm{FFTS})$ \\
standard retrieval & \\
\hline
\end{tabular}

curve, whereas the red line represents the $15 \mathrm{MHz}$ frequency binned spectrum.

Compared to the FB, the FFTS has a high resolution not only in the centre but also in the line wings. The stability time of our whole radiometer system was improved compared to the FB (Müller et al., 2009). The FB required much more maintenance by the operator, and in spite of this individual channels were disturbed from time to time so that the measured line spectrum was not usable. With the aim to ensure a proper harmonisation of the two data sets, both spectrometers were measuring in parallel for over 2 years. Afterwards the FB was turned off, and the FFTS is now used to continue the ozone time series. Table 1 summarises the characteristics of the GROMOS radiometer. 


\subsection{Measurement principle and retrieval procedure}

GROMOS measures the thermal microwave emission of a rotational transition of ozone at $142.175 \mathrm{GHz}$. As the observed emission line is broadened by pressure, the vertical distribution of ozone (approximately from 25 to $70 \mathrm{~km}$ ) can be calculated from the shape of the observed spectrum in the retrieval procedure. For the ozone profile retrieval of GROMOS, the Atmospheric Radiative Transfer Simulator (ARTS2) (Eriksson et al., 2011) is used as the forward model. It simulates atmospheric radiative transfer and calculates an ozone line spectrum for a model atmosphere using an a priori ozone profile. The accompanying Matlab package Qpack2 (Eriksson et al., 2005) takes advantage of ARTS2 by comparing the modelled spectrum with the observed ozone spectrum of GROMOS. The Qpack2 derives the best estimate of the vertical profile of the ozone volume mixing ratio (VMR) by using the optimal estimation method (OEM) (Rodgers, 1976) and, taking into account the uncertainties of the measured ozone spectrum, the a priori profile and the a priori covariance matrix. The OEM further provides a characterisation and formal analysis of the uncertainties (Rodgers, 1990).

Prior to the inversion, a tropospheric correction for the tropospheric attenuation (mainly due to water vapour) of stratospheric ozone emission is applied to the calibrated spectra by assuming an isothermal troposphere with a mean temperature, $T_{\text {mean }} . T_{\text {mean }}$ depends upon the temperature profile as well as on the absorption profile at a specific frequency. Since the number density is highest at low altitudes and the absorption is highest near the ground, $T_{\text {mean }}$ has a value close to the temperature of the lower troposphere (Ingold et al., 1998). The transmission factor $e^{-\tau}=\left(T_{\mathrm{B} \text {, wing }}-T_{\text {mean }}\right) /\left(T_{\mathrm{B} \text {, strat }}-\right.$ $T_{\text {mean }}$ ), where $\tau$ is the opacity, is estimated from the offresonance emission $T_{\mathrm{B} \text {, wing }}$ at the wings of the spectrum and the expected brightness temperature above the troposphere $T_{\mathrm{B} \text {,strat }}$ (Peter, 1997). Knowledge of the tropospheric opacity permits the so-called tropospheric correction, which means that the effect of tropospheric attenuation is removed from the measured line spectrum (Studer et al., 2014). The inversion is performed for all spectra if the tropospheric opacity is lower than 1.6, i.e. if the transmission factor is larger than 0.2 (Studer et al., 2013). In the standard retrieval, the time resolution is $30 \mathrm{~min}$, which gives a sufficient signal-to-noise ratio (approximately 30; measurement noise is around $0.7 \mathrm{~K}$, and brightness temperature at the ozone line peak is around $20 \mathrm{~K}$ ) (Studer et al., 2014). The vertical resolution depends upon altitude and can be estimated from the full width at half maximum (FWHM) of a kernel line. The averaging kernels (AVKs) and the area of the averaging kernels (AoA) of GROMOS are shown on the middle and right panel of Fig. 3. For GROMOS the vertical resolution lies generally within 8 $12 \mathrm{~km}$ in the stratosphere and increases with altitude to 20 $25 \mathrm{~km}$ in the lower mesosphere. An estimate of the a priori contribution to the retrieval can be obtained by the area of the averaging kernels (measurement response). Between 20 and

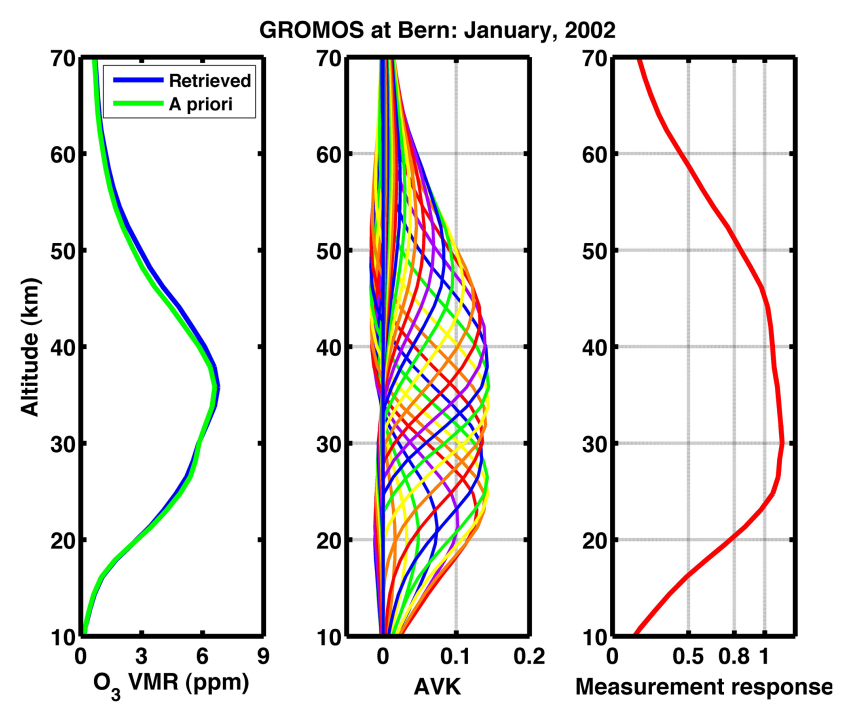

Figure 3. Example of an a priori profile and a retrieved ozone profile (left panel), averaging kernels (middle panel) and the measurement response (area of averaging kernels) (right panel) of the GROMOS retrieval for January, 2002.

$52 \mathrm{~km}(50$ to $0.5 \mathrm{hPa})$ the measurement response is higher than 0.8 , which corresponds to an a priori contribution less than $20 \%$. Consequently, the retrieved ozone values at these altitudes are predominantly based on the measured line spectrum.

The a priori profiles of ozone are from a monthly varying climatology based on earlier ozone measurements at Bern. As diagonal elements of the a priori covariance matrix we assume a relative error around $35 \%$ at $100 \mathrm{hPa}$. The error decreases in the lower stratosphere up to $28 \%$. Then it increases linearly from $35 \%$ in the upper stratosphere to $70 \%$ in the lower mesosphere. The off-diagonal elements exponentially decrease with a correlation length of $3 \mathrm{~km}$. The line shape used in the retrieval is the representation of the Voigt line profile from Kuntz (1997). Spectroscopic parameters to calculate the ozone absorption coefficients were taken from the JPL catalogue (Picket et al., 1998) and the HITRAN spectroscopic database (Rothman et al., 1998). The atmospheric temperature and pressure profiles are taken from the 6-hourly European Centre for Medium-Range Weather Forecast (ECMWF) operational analysis data and are extended above $80 \mathrm{~km}$ by monthly mean temperatures of the CIRA86 atmosphere model (Fleming et al., 1990). The total error includes systematic error and random error as well as the smoothing term. The systematic error originates from the tropospheric correction, calibration error due to systematic errors in the load temperatures, errors due to baseline features, spectral parameters, etc. The random error includes, e.g., the thermal noise on the spectra. An error analysis has been performed by Peter (1997). The uncertainty resulting from the tropospheric correction is smaller than $5 \%$ (Ingold 
et al., 1998). The total error is of the order of $7 \%$ for the stratosphere and increases toward the lower and upper altitude limit: up to $10 \%$ at $20 \mathrm{~km}$ and up to $30 \%$ at $70 \mathrm{~km}$. The smoothing term is due to the limited altitude resolution. The GROMOS radiometer is described in more detail by Peter (1997).

\section{Harmonisation strategy for the ozone profiles}

As GROMOS was upgraded with a fast Fourier transform spectrometer, harmonisation is needed between the time series measured by the original FB spectrometer and the time series recorded by FFTS. In order to ensure appropriate harmonisation, both spectrometers were measuring in parallel for over 2 years. According to Sect. 2.2, the FFTS offers high resolution besides stability and accuracy compared with FB. Therefore, we can use the data recorded by FFTS as a reference for the original FB data set.

The strategy carried out for the harmonisation of both data sets was to study the bias between them in the time interval in which both spectrometers were simultaneously measuring, i.e. from October 2009 to August 2011. In Fig. 4, we show in the left panel the mean ozone profiles recorded by FB (red line) and by FFTS (blue line), for this time interval. The blue area (FFTS) and the red area (FB) are the standard deviation of the measurements. The middle panel presents the mean relative difference profile between data of both spectrometers, with the FFTS data as a reference. The grey area represents the standard deviation of the differences. The bias between FB and FFTS during this overlap period is less than $5 \%$ above $20 \mathrm{hPa}$. The green box indicates the valid range of GROMOS (from 30 to $0.3 \mathrm{hPa}$ ). The purpose of the harmonisation is to correct this bias between both spectrometers, by using the data from FFTS as a reference. Accordingly, the harmonisation was performed by subtracting the mean absolute difference profile (blue curve in the right panel) from the FB data set, for every pressure level.

On the basis of this harmonisation process, we have generated a time series of more than 20 years of stratospheric ozone profiles observed by GROMOS over Bern (Fig. 5). Undoubtedly, Fig. 5 provides an extremely clear view of the evolution of stratospheric ozone over the last 2 decades at a central Europe station, and hence at northern midlatitudes. Further, the annual cycle of ozone can be observed in the stratosphere, as can an increase of mid-stratospheric ozone in recent years.

\section{Trend estimation method}

A multilinear parametric trend model (von Clarmann et al., 2010) is applied to the time series of ozone monthly means by fitting the following regression function to the data from January 1997 to January 2015:

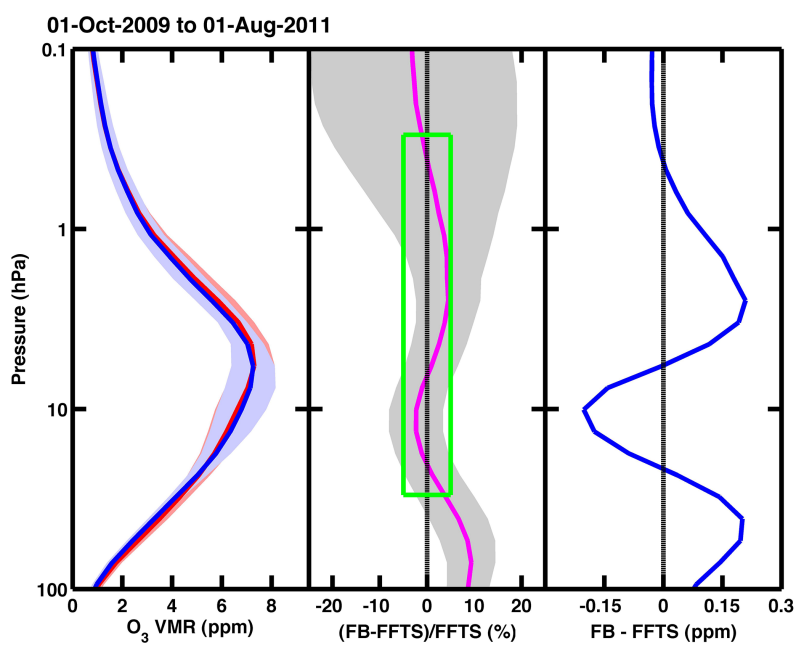

Figure 4. Harmonisation of ozone profiles retrieved from the FB (red line in the left panel) and FFT (blue line in the left panel) spectrometers. The blue area (FFTS) and the red area (FB) are the standard deviation of the measurements. The bias between FB and FFTS is less than $5 \%$ (middle panel) as derived from the overlap measurement (2009 to 2011) of ozone profiles at pressure levels from 30 to $0.3 \mathrm{hPa}$ (valid altitude range of GROMOS, green box). The grey area in the middle panel is the standard deviation of the differences.

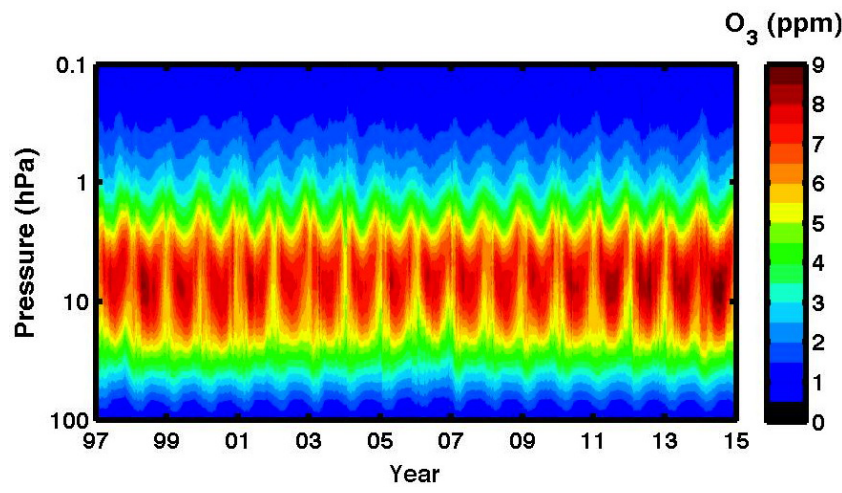

Figure 5. Harmonised time series of stratospheric ozone VMR profiles recorded by GROMOS from January 1997 to January 2015 above Bern, Switzerland.

$$
\begin{aligned}
& \hat{y}(t)=a+b \cdot t+c_{1} \cdot q b o_{1}(t)+d_{1} \cdot q b o_{2}(t)+e \cdot F 10.7(t) \\
& +f \cdot \operatorname{MEI}(t)+\sum_{n=2}^{m}\left(c_{n} \cdot \sin \left(\frac{2 \pi \cdot t}{l_{n}}\right)+d_{n} \cdot \cos \left(\frac{2 \pi \cdot t}{l_{n}}\right)\right),
\end{aligned}
$$

where $t$ is time, and $a$ and $b$ represent the constant term and the slope of the fit, respectively. The terms $q b o_{1}$ and $q b o_{2}$ are the normalised Singapore zonal winds at 30 and $50 \mathrm{hPa}$ as provided by the Free University of Berlin via http://www.geo.fu-berlin.de/met/ag/strat/ produkte/qbo/index.html. These wind series are approximately orthogonal such that their combination can emulate 


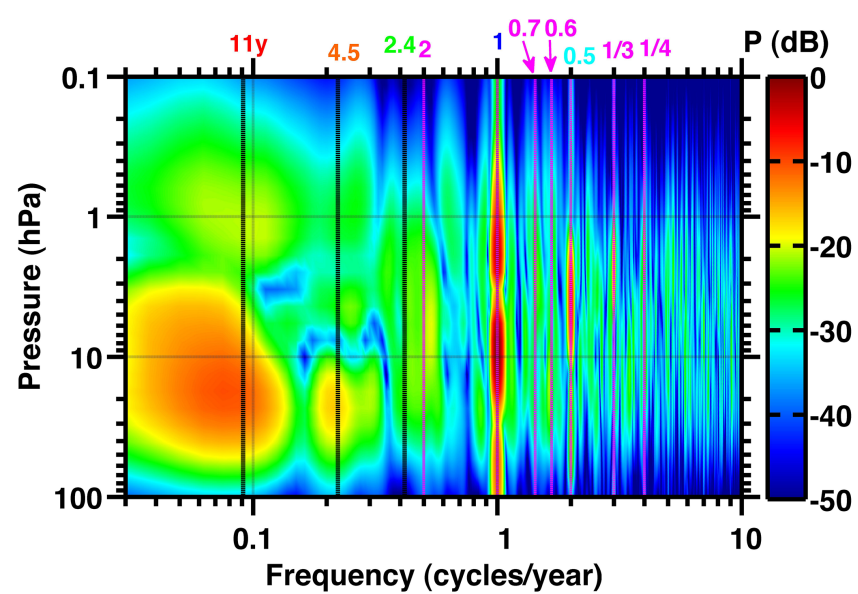

Figure 6. Power spectra of stratospheric ozone time series measured by GROMOS above Bern, Switzerland. The black dotted lines are the frequencies for the annual and semi-annual oscillation, the 11 years due to the solar cycle, the 2.4 years of the QBO and the 4.5 years of ENSO phenomenon. The magenta dotted lines are the frequencies of the overtones (3, 4, 7.2, 8.4 and 24 months).

any quasi-biennial oscillation (QBO) phase shift (Kyrölä et al., 2010). The F10.7 term stands for fitting against the solar $10.7 \mathrm{~cm}$ flux, which is commonly used as a measure of solar activity. MEI is the multivariate ENSO index (MEI), which monitors the El Niño-Southern Oscillation (ENSO) phenomenon with six variables (sea-level pressure, zonal and meridional components of the surface wind, sea surface temperature, surface air temperature, and total cloudiness fraction of the sky). Both indices are available from www.esrl. noaa.gov/psd/data/climateindices/list. The sum term comprises seven sine and cosine functions with the period length $l_{n}$, including the annual and semi-annual oscillation as well as five harmonics with periods lengths of 3, 4, 7.2, 8.4 and 24 months. The selection of these periods lengths was done by plotting the power spectra of the GROMOS ozone series (Fig. 6). In black dotted lines are represented the frequencies for the annual and semi-annual oscillation, the 11-year oscillation due to the solar cycle, the 2.4 years characteristic of the QBO and the 4.5-year frequency related to the ENSO phenomenon. In magenta dotted lines are plotted the spectral components of 24, 8.4, 7.2, 4 and 3 months.

With the aim to assess the linear variation of the time series within the period covering January 1997 to January 2015, the coefficients $a, b, c_{1}, \ldots, c_{8}, d_{1}, \ldots, d_{8}, e$ and $f$ are fitted to the ozone monthly means using the method of von Clarmann et al. (2010), where the full error covariance matrix of mixing ratios is considered. The diagonal elements of the error covariance matrix are the uncertainty of the ozone monthly mean profiles, described in the following section. The offdiagonal elements are initially set to 0 . In a second iteration, the correlation coefficients between each data point and its $n$th neighbour are estimated from the fit residuals, and an

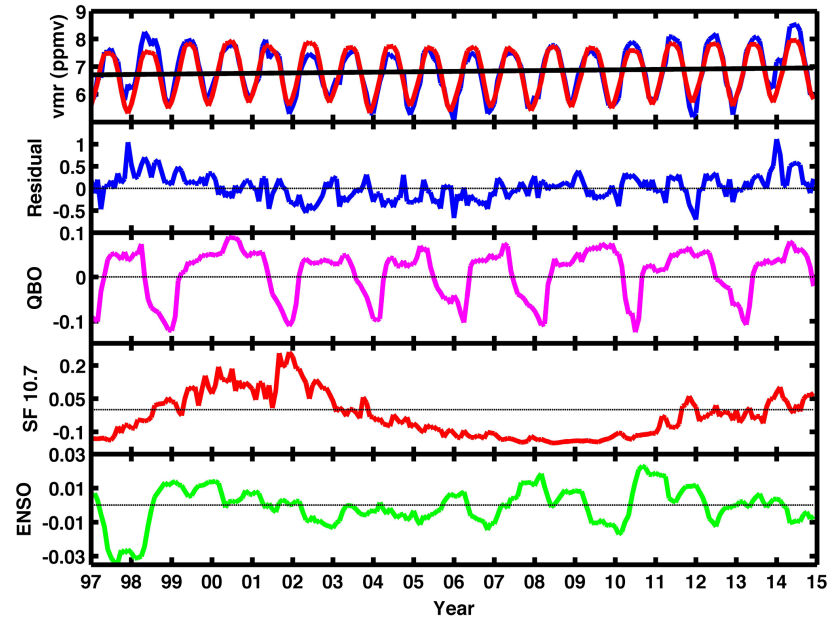

Figure 7. The first panel shows the trend fit at $10 \mathrm{hPa}$, with the GROMOS monthly mean data (blue line), the calculated fit (red line) and the related trend (black line). The second panel shows the residual and in the following panels the fitted signals of the proxies QBO (magenta line), solar F10.7 cm flux (red line) and ENSO (green line), at $10 \mathrm{hPa}$.

additional error term is built, based on these covariances, describing the deficiency of the multi-parametric model chosen. This error term (in terms of covariance matrix) is scaled according to chi-square statistics and added to the initial measurement error covariance matrix.

The inputs required by the trend estimation program are the ozone monthly mean profiles and their uncertainty. An example of the fit is displayed in Fig. 7, showing the ozone monthly means as well as the fit and linear variation (top panel) and the residual (second panel) at $10 \mathrm{hPa}$. The following panels show the ozone fitted signals of the proxies QBO (magenta line), solar F10.7 cm flux (red line) and ENSO (green line), also at $10 \mathrm{hPa}$. The variability of the GROMOS measurements is satisfactorily reproduced by the fit. The residual is within 0.5 ppmv except for some particular cases. There are just some small short-term anomalies in the years 1998, 2012 and 2014, probably due to the effect of an atmospheric variability on a larger timescale which is not accounted for by the multilinear trend model. From 20 to $0.1 \mathrm{hPa}$ the regression model explains about $80 \%$ of the variance.

\section{Uncertainty considerations}

Before analysing the estimated trends, the uncertainties affecting the ozone profiles recorded by GROMOS must be considered, analysed and taken into account. We have considered three types of uncertainties. The first one is the uncertainty of the natural variability that is approximated by the standard error of the monthly mean. The second one is the observation error, which is obtained from the propagation 
of the thermal noise of the brightness temperature into the ozone profile. The observation error corresponds to the random error, calculated during the retrieval procedure, which is due to the thermal noise on the spectra. The third way to assess the uncertainties is based on cross-validations of GROMOS with satellites and ground-based instruments (Dumitru et al., 2006; Steinbrecht et al., 2006; Studer et al., 2013; Delcloo and Kreher, 2013).

The criterion to indicate if an estimated trend is statistically significant at the $95 \%$ confidence level is that the absolute ratio of the trend to its uncertainty is larger than 2 (Tiao et al., 1990).

The large number of GROMOS measurements per month allows a robust assessment of the uncertainty from natural variability, where the effect of the autocorrelation among data points within the series is taken into account. The standard error of the monthly mean contains uncertainties due to both measurement noise and atmospheric variability. First the standard deviation was calculated:

$\sigma=\sqrt{\frac{1}{n-1} \sum_{i=1}^{n}\left(x_{i}-\bar{x}\right)^{2}}$,

where $n$ is the number of measurements per month, $x$ the ozone mixing ratio, and $\bar{x}$ its monthly mean. Then the variability within the month was analysed for autocorrelations between the single measurements. From this information, the degrees of freedom (DGF) were estimated as the ratio between the number of measurements $n$ and the correlation length within the month under assessment. Due to the autocorrelations, DGF is less than the number of measurements. For instance if the amount of measurements of GROMOS within a month is around 1300 , and at $10 \mathrm{hPa}$ the time lag is around 2 days, then the DGF are more or less 12.5. Following the same assumption, at $100 \mathrm{hPa}$ (time lag around 5 days) the DGF are 4.8 and 81.25 at $1 \mathrm{hPa}$ ( $8 \mathrm{~h}$ of time lag). With DGF, the standard error of the monthly mean (SEM) can be calculated:

$\mathrm{SEM}=\frac{\sigma}{\sqrt{\mathrm{DGF}}}=\frac{1}{\sqrt{(n-1) \mathrm{DGF}}} \sqrt{\sum_{i=1}^{n}\left(x_{i}-\bar{x}\right)^{2}}$.

To calculate the correlation lengths, we used the autocorrelation function (ACF) of Matlab, which provides us the time lags (correlation lengths) of the temporal autocorrelation function calculations. For stationary processes, the autocorrelation among any two observations only depends on the time lag. Therefore, the autocorrelation is 1 for the time lag equal to 0 , since unlagged data are perfectly correlated with themselves. The collection of autocorrelations, autocorrelation function, computed for various lags exhibit a more or less gradual decay toward 0 as the time lag increases, reflecting the generally weaker statistical relationship between data points more remote from each other in time. The number

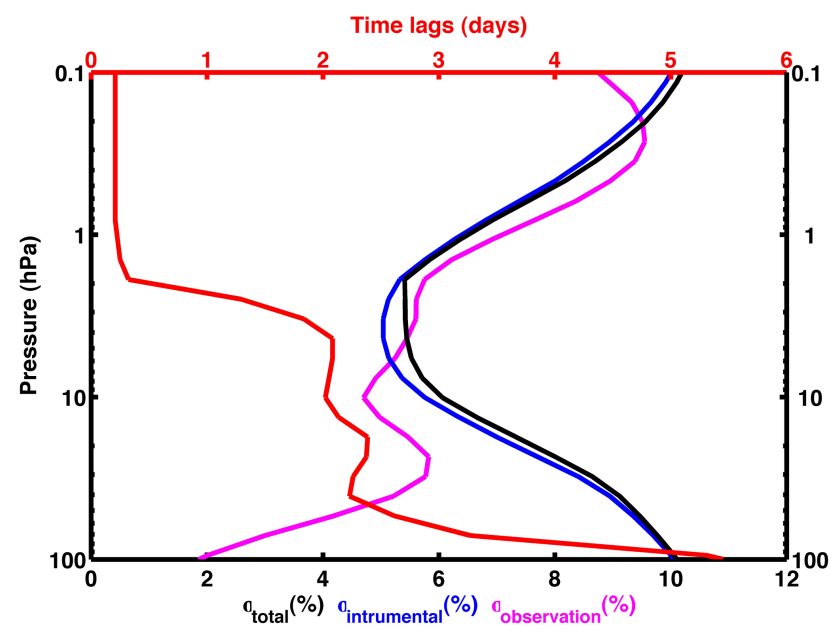

Figure 8. Uncertainty budget of GROMOS used in the trend analysis. The red line is an example of monthly mean correlation length profile, in units of days, calculated for the time interval from October 2011 to October 2014. The magenta line is the monthly mean observation error profile, calculated for the same time interval. The blue line is the estimated instrumental error profile. And the black line represents the total contribution of the uncertainty of GROMOS.

of time lags of autocorrelated values within the $95 \%$ confidence level are the correlation lengths within a month, used to calculate the DGF.

Finally, we assume an uncorrelated monthly instrumental uncertainty. The aim is to take into account the bias between GROMOS and other instruments, and thereby to get a realistic uncertainty estimation. We have estimated this profile with the result of past cross-validations of coincident data from GROMOS, ozonesondes, nearby lidars and satellites (Dumitru et al., 2006; Steinbrecht et al., 2006; Studer et al., 2013 and Delcloo and Kreher, 2013). Past cross-validations show a systematic uncertainty of about 5 to $10 \%$ for our instrument: around $5 \%$ between 10 and $1 \mathrm{hPa}$ and tending to roughly $10 \%$ toward the lower and upper stratosphere. The strongest point of this estimation method relies on the fact that these validation reports and intercomparisons cover all 20 years of GROMOS measurements - both for the period in which the spectral analysis was done by the filter bench spectrometer (Dumitru et al., 2006; Steinbrecht et al., 2006), as for the period of the new fast Fourier transform spectrometer (Studer et al., 2013; Delcloo and Kreher, 2013).

Figure 8 shows the error budget used as input for the trend estimation model. The red line is an example of monthly mean correlation length profile, in units of days, calculated for the time interval from October 2011 to October 2014. We can see the monthly autocorrelations of stratospheric ozone. The magenta line is the monthly mean observation error profile, from the thermal noise on the spectra, calculated for the same time interval. The blue line is the estimated instrumental error profile based on recent and past intercomparisons of 


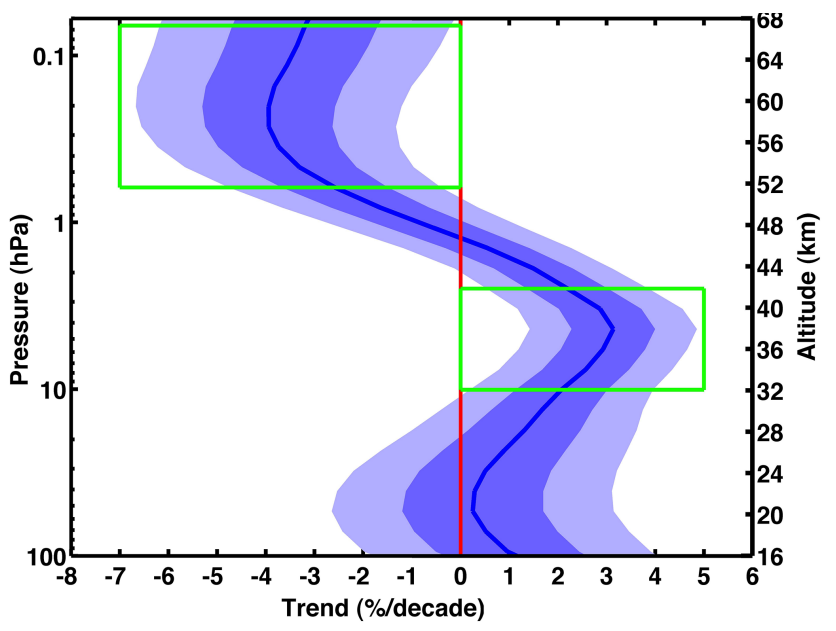

Figure 9. Estimated ozone trend profile (in $\%$ decade $^{-1}$ ) for the period of January 1997 to January 2015 recorded by GROMOS above Bern, Switzerland. The dark blue line represents the trend profile; the darkest blue area and the lightest blue area are the $1 \sigma$ and $2 \sigma$ areas, respectively. $\sigma$ is the uncertainty of the trend estimate. The green boxes are the two regions where the trend is statistically significant at the $95 \%$ confidence level.

coincident data from GROMOS, ozonesondes, nearby lidars and satellites. And the black line represents the total contribution of the uncertainty of GROMOS, taking into account all the aforementioned errors.

\section{Results and discussion}

Figure 9 presents the estimated ozone trend profile (in $\%$ decade $^{-1}$ ) for the period of January 1997 to January 2015 above Bern, Switzerland. The selection of the time interval is based on the assumption that 1997 is the turnaround year of the equivalent effective stratospheric chlorine (EESC), since EESC concentration peaked in 1997 at midlatitudes (WMO, 2011). The dark blue line represents the trend profile; the dark blue area and the light blue area are the $1 \sigma$ and $2 \sigma$ areas, respectively. $\sigma$ is the uncertainty of the trend estimate. The green boxes are the two regions where the trend is statistically significant at the $95 \%$ confidence level. These features of particular interest are readily identified: the first green box of positive trend between 10 and $2.5 \mathrm{hPa}$ ( 32 to $42 \mathrm{~km}$ ) with its maximum peak at $(3.14 \pm 1.71)\left(\% \mathrm{decade}^{-1}\right)$ around $4.36 \mathrm{hPa}$, and the second green box of negative trend between 0.6 and $0.06 \mathrm{hPa}$ (50 to $67 \mathrm{~km}$ ) with its maximum peak at $(-3.94 \pm 2.73)\left(\%\right.$ decade $\left.^{-1}\right)$ around $0.2 \mathrm{hPa}$. The uncertainty denotes twice the standard deviation.

The estimated stratospheric trend results are able to support the evidence of a shift toward increasing ozone in the middle and upper stratosphere at northern midlatitudes also reported by previous studies (Vigouroux et al., 2008; Nair et al., 2013; Huang et al., 2014; WMO, 2014; Tummon et al., 2015; and references therein). On the other hand, other recent studies (Eckert et al., 2014; Vigouroux et al., 2015; Harris et al., 2015; and references therein) have found a positive but not significant trend at our location. But we have to be careful about these discrepancies since they could arise from differences in treatment and propagations of uncertainties, selection of data, ozone measurement techniques, statistical approach, latitudinal and altitudinal extent and/or the time period covered in the trend study.

The WMO (2014, Table 2.4) reported a statistically significant ozone increase of $(3.9 \pm 1.3)\left(\%\right.$ decade $\left.^{-1}\right)$ at $40 \mathrm{~km}$ in the upper stratosphere at northern midlatitudes $\left(35-60^{\circ} \mathrm{N}\right)$ over the 2000-2013 period. This ozone trend value is based on observations from various space-based and ground-based measurement instruments. A slightly different ozone series of the GROMOS instrument contributed a bit to the ozone trend estimation of WMO (2014). The ozone trend of our study cannot be directly compared to WMO (2014) since the time window and the measurement region differ. However, the ozone trend at Bern (about $3.0 \%$ decade $^{-1}$ at $40 \mathrm{~km}$ ) agrees well with the ozone trend at northern midlatitudes (about $3.9 \% \mathrm{decade}^{-1}$ at $40 \mathrm{~km}$ ) as reported by WMO (2014). Furthermore, Nair et al. (2013) presented positive upper-stratospheric ozone trends, in the 1997-2010 period, over a northern midlatitude station, Haute-Provence Observatory (OHP: $43.93^{\circ} \mathrm{N}, 5.71^{\circ} \mathrm{E}$ ), using GOZCARDS (Global OZone Chemistry And Related trace gas Data records for the Stratosphere) data and a combination of data sets from total column ozone observations from the Dobson and Système d'Analyse par Observation Zénithale (SAOZ) spectrometers and ozone profile measurements from light detection and ranging (lidar), ozonesondes, the Stratospheric Aerosol and Gas Experiment (SAGE) II, the Halogen Occultation Experiment (HALOE) and the Aura Microwave Limb Sounder (MLS). Our results also match well with those reported in WMO (2010) and by Vigouroux et al. (2008), who deduced a positive trend of $(0.26 \pm 0.18)\left(\%\right.$ year $\left.^{-1}\right)$ at Jungfraujoch for the period 1995-2004 in the altitude range of $27-42 \mathrm{~km}$. The Jungfraujoch station located in Switzerland at $47^{\circ} \mathrm{N}$ is equipped with a Fourier transform infrared (FTIR) instrument. Moreover, Tummon et al. (2015) showed, with Solar Backscatter Ultraviolet Radiometer (SBUV) instruments on board NASA (National Aeronautics and Space Administration) and NOAA (National Oceanographic and Atmospheric Administration) satellites, significant positive trends up to $4 \%$ decade $^{-1}$ between 10 and $7 \mathrm{hPa}$, for the 1998-2011 period. All these statements are in agreement with our findings. The small change in trends is somewhat to be expected given that the lifetimes of most ODS species are long (several decades), and thus the removal of these species will occur over a considerably longer timescale than the relatively brief period during which their concentrations increased (Tummon et al., 2015). Otherwise, the increase of carbon dioxide is cooling the upper stratosphere. This cool- 
ing increases ozone concentrations in this region through temperature-dependent chemistry (WMO, 2014).

Concerning circulation changes as contributors to the stratospheric ozone increases, recent studies have simulated changes in the Brewer-Dobson circulation (BDC) in response to increasing greenhouse gases (Butchart et al., 2006). Changes in the BDC can modify the distribution of ozone and other chemical compounds. Recently this stratospheric mean meridional circulation (BDC) has been clearly differentiated into two branches: a shallow branch, located in the lowermost stratosphere, with upwelling in the tropics and downwelling in the subtropics and middle latitudes, and a deep branch with maximum upwelling in the tropical upper stratosphere and downwelling in the middle and high latitudes throughout the entire height of the stratosphere (Birner and Bönisch, 2011). Observations of changes in temperature and ozone over the past 3 to 5 decades are suggestive of increased upwelling of air in the tropical lower stratosphere. This is consistent with model simulations, which robustly simulate long-term increases in the tropical upwelling due to past greenhouse gas increases (WMO, 2014). Ozone in the tropical lower stratosphere shows little response to ODS, because conversion of ODS into reactive chlorine and bromine is small in this region. Instead, tropical lower-stratospheric ozone is more affected by the strength of tropical upwelling of air from the troposphere to stratosphere caused by the shallow branch of the BDC (WMO, 2014). Additionally, Stiller et al. (2012) also used the hypothesis of a general increased upwelling in the tropics and intensification of the BDC, together with weakening of the subtropical mixing barrier as an explanation of their age of air temporal evolution. Therefore, the acceleration of both branches of BDC could be one of the contributors to the aforementioned stratospheric ozone increase in northern midlatitudes.

Regarding the lower mesosphere region, our results are in agreement with recent trend estimations (Kyrölä et al., 2013; Remsberg, 2014, and references therein; Tummon et al., 2015). They have found statistically significant negative trends above $55 \mathrm{~km}$ in the northern midlatitudes through the SAGE II version 7 data and by the combined SAGE II-GOMOS (Global Ozone Monitoring by Occultation of Starts) data set.

\section{Conclusions}

We have constructed a harmonised ozone profile time series from GROMOS measurements since November 1994 up to now. The need for such harmonisation is due to the spectrometer upgrade performed in 2009. From November 1994 to October 2011, the ozone line spectra were measured by a filter bench spectrometer. Since July 2009 the spectral analysis has been done by a fast Fourier transform spectrometer. Both spectrometers were measuring parallel in order to ensure a proper harmonisation. A bias between both data sets has been identified, being less than $5 \%$ above $20 \mathrm{hPa}$. The harmonisation has been done by taking the data set from the FFTS as a reference for the FB. The combined data set time series was then analysed for trends in the stratosphere.

A mutilinear parametric trend model was used to analyse this time series of stratospheric ozone profiles. This model includes a linear term, the solar variability, the El NiñoSouthern Oscillation index, the quasi-biennial oscillation, the annual and semi-annual oscillation and several harmonics with period lengths between 3 and 24 months. The trend results for the period between January 1997 and January 2015 show statistically significant trends at the $95 \%$ confidence level at pressure levels around 5 and $0.2 \mathrm{hPa}$. Our estimated trend profile is in agreement with other northern midlatitude trend estimations from other ground-based and satellite instruments (Vigouroux et al., 2008; Nair et al., 2013; Kyrölä et al., 2013; Huang et al., 2014; Remsberg, 2014; WMO, 2014; Tummon et al., 2015, and references therein).

This study also demonstrates the reliability of GROMOS measurements for providing stratospheric ozone profiles, allowing us the adequate study of the characterisation of ozone variability on timescales from 10 min to more than 20 years. The continuation in time of these measurements will help future generations to confirm findings through the intercomparison with other instruments and to understand the evolution of the ozone layer, which is extremely crucial for life on Earth.

Acknowledgements. This work was supported by the Swiss National Science Foundation under Grant 200020 - 160048 and MeteoSwiss GAW Project: "Fundamental GAW parameters measured by microwave radiometry".

Edited by: S. Godin-Beekmann

\section{References}

Birner, T. and Bönisch, H.: Residual circulation trajectories and transit times into the extratropical lowermost stratosphere, Atmos. Chem. Phys., 11, 817-827, doi:10.5194/acp-11-817-2011, 2011.

Butchart, N., Scaife, A. A., Bourqui, M., de Grandpré, J., Hare, S. H. E., Kettleborough, J., Langematz, U., Manzini, E., Sassi, F., Shibata,K., Shindell, D., and Sigmond, M.: Simulations of anthropogenic change in the strength of the Brewer-Dobson circulation, Clim. Dynam., 27, 727-741, doi:10.1007/s00382-0060162-4, 2006.

Delcloo, A. and Kreher, K.: O3M SAF Validation report, Finish Meteorological Institute, available at: http://o3msaf.fmi.fi/docs/vr/ Validation_Report_NOP_NHP_OOP_OHP_Jun_2013.pdf (last access: 16 June 2015), 2013.

Dumitru, M. C., Hocke, K., Kämpfer, N., and Calisesi, Y.: Comparison and validation studies related to ground-based microwave observations of ozone in the stratosphere and mesosphere, J. Atmos. Sol.-Terr. Phy., 68, 745-756, 2006. 
Eckert, E., von Clarmann, T., Kiefer, M., Stiller, G. P., Lossow, S., Glatthor, N., Degenstein, D. A., Froidevaux, L., GodinBeekmann, S., Leblanc, T., McDermid, S., Pastel, M., Steinbrecht, W., Swart, D. P. J., Walker, K. A., and Bernath, P. F.: Drift-corrected trends and periodic variations in MIPAS IMK/IAA ozone measurements, Atmos. Chem. Phys., 14, 25712589, doi:10.5194/acp-14-2571-2014, 2014.

Eriksson, P., Jiménez, C., and Buehler, S. A.: Qpack, a general tool for instrument simulation and retrieval work, J. Quant. Spectrosc. Ra., 91, 47-64, doi:10.1016/j.jqsrt.2004.05.050, 2005.

Eriksson, P., Buehler, S. A., Davis, C. P., Emde, C., and Lemke, O.: ARTS, the atmospheric radiative transfer simulator, Version 2, J. Quant. Spectrosc. Ra., 112, 1551-1558, doi:10.1016/j.jqsrt.2011.03.001, 2011.

Fleming, E. L., Chandra S., Barnett J. J., and Corney, M.: Zonal mean temperature, pressure, zonal wind, and geopotential height as functions of latitude, COSPAR International Reference Atmosphere: 1986, Part II: Middle Atmosphere Models, Adv. Space Res., 10, 12, 11-59, doi:10.1016/0273-1177(90)90386-E, 1990.

Harris, N. R. P., Hassler, B., Tummon, F., Bodeker, G. E., Hubert, D., Petropavlovskikh, I., Steinbrecht, W., Anderson, J., Bhartia, P. K., Boone, C. D., Bourassa, A., Davis, S. M., Degenstein, D., Delcloo, A., Frith, S. M., Froidevaux, L., Godin-Beekmann, S., Jones, N., Kurylo, M. J., Kyrölä, E., Laine, M., Leblanc, S. T., Lambert, J.-C., Liley, B., Mahieu, E., Maycock, A., de Mazière, M., Parrish, A., Querel, R., Rosenlof, K. H., Roth, C., Sioris, C., Staehelin, J., Stolarski, R. S., Stübi, R., Tamminen, J., Vigouroux, C., Walker, K. A., Wang, H. J., Wild, J., and Zawodny, J. M.: Past changes in the vertical distribution of ozone - Part 3: Analysis and interpretation of trends, Atmos. Chem. Phys., 15, 9965-9982, doi:10.5194/acp-15-9965-2015, 2015.

Huang, F. T., Mayr, H. G., Russell III, J. M., and Mlynczak, M. G.: Ozone and temperature decadal trends in the stratosphere, mesosphere and lower thermosphere, based on measurements from SABER on TIMED, Ann. Geophys., 32, 935-949, doi:10.5194/angeo-32-935-2014, 2014.

Ingold, T., Peter, R., and Kämpfer, N.: Weighted mean tropospheric temperature and transmittance determination at milimeter-wave frequencies for ground-based application, Radio Sci., 33, 905918, 1998.

Keckhut, P., Hauchecorne, A., Blanot, L., Hocke, K., GodinBeekmann, S., Bertaux, J.-L., Barrot, G., Kyrölä, E., van Gijsel, J. A. E., and Pazmino, A.: Mid-latitude ozone monitoring with the GOMOS-ENVISAT experiment version 5: the noise issue, Atmos. Chem. Phys., 10, 11839-11849, doi:10.5194/acp10-11839-2010, 2010.

Kyrölä, E., Tamminen, J., Sofieva, V., Bertaux, J. L., Hauchecorne, A., Dalaudier, F., Fussen, D., Vanhellemont, F., Fanton d'Andon, O., Barrot, G., Guirlet, M., Fehr, T., and Saavedra de Miguel, L.: GOMOS $\mathrm{O}_{3}, \mathrm{NO}_{2}$, and $\mathrm{NO}_{3}$ observations in 2002-2008, Atmos. Chem. Phys., 10, 7723-7738, doi:10.5194/acp-10-77232010, 2010.

Kyrölä, E., Laine, M., Sofieva, V., Tamminen, J., Päivärinta, S.-M., Tukiainen, S., Zawodny, J., and Thomason, L.: Combined SAGE II-GOMOS ozone profile data set for 1984-2011 and trend analysis of the vertical distribution of ozone, Atmos. Chem. Phys., 13, 10645-10658, doi:10.5194/acp-13-10645-2013, 2013.
Kuntz, M.: A new implementation of the Humlicek algorithm for the calculation of the Voigt profile function, J. Quant. Spectrosc. Ra., 57, 819-824, doi:10.1016/S0022-4073(96)00162-8, 1997.

Molina, M. J. and Rowland, F. S.: Stratospheric sink for chlorofluoromethanes: Chlorine atom catalyzed destruction of ozone, Nature, 249, 810-812, doi:10.1038/249810a0, 1974.

Müller, S., Murk A., Monstein, C., and Kämpfer, N.: Intercomparison of digital Fast Fourier Transform and Acoustooptical Spectrometers for microwave radiometry of the atmosphere, IEEE T. Geosci. Remote, 47, 2233-2239, doi:10.1109/TGRS.2009.2013695, 2009.

Nair, P. J., Godin-Beekmann, S., Kuttippurath, J., Ancellet, G., Goutail, F., Pazmiño, A., Froidevaux, L., Zawodny, J. M., Evans, R. D., Wang, H. J., Anderson, J., and Pastel, M.: Ozone trends derived from the total column and vertical profiles at a northern mid-latitude station, Atmos. Chem. Phys., 13, 10373-10384, doi:10.5194/acp-13-10373-2013, 2013.

Newchurch, M. J., Yang, E.-S., Cunnold, D. M., Reinsel, G. C., Zawodny, J. M., and Russell III, J. M.: Evidence for slowdown in stratospheric ozone loss: First stage of ozone recovery, J. Geophys. Res., 108, 4507, doi:10.1029/2003JD003471, 2003.

Palm, M., Hoffmann, C. G., Golchert, S. H. W., and Notholt, J.: The ground-based MW radiometer OZORAM on Spitsbergen - description and status of stratospheric and mesospheric $\mathrm{O}_{3}$-measurements, Atmos. Meas. Tech., 3, 1533-1545, doi:10.5194/amt-3-1533-2010, 2010.

Parrish, A., Connor, B. J., Tsou, J. J., McDermid, I. S., and Chu, W. P.: Ground-based microwave monitoring of stratospheric ozone, J. Geophys. Res., 97, 2541-2546, doi:10.1029/91JD02914, 1992.

Peter, R.: The ground-based millimeter-wave ozone spectrometerGROMOS, IAP Research Report, University of Bern, Bern, Switzerland, 13, 1997.

Pickett, H. M., Poynter, R. L., Cohen, E. A., Delitsky, M. L., Pearson, J. C., and Müller, H. S. P.: Submillimeter, millimeter, and microwave spectral line catalog, J. Quant. Spectrosc. Ra., 60, 883-890, doi:10.1016/S0022-4073(98)00091-0, 1998.

Remsberg, E. E.: Decadal-scale responses in middle and upper stratospheric ozone from SAGE II version 7 data, Atmos. Chem. Phys., 14, 1039-1053, doi:10.5194/acp-14-1039-2014, 2014.

Rodgers, C. D.: Retrieval of atmospheric temperature and composition from remote measurements of thermal radiation, Rev. Geophys. Space Ge., 14, 609-624, 1976.

Rodgers, C. D.: Characterisation and error analysis of profiles retrieved from remote sounding measurements, J. Geophys. Res.Atmos., 95, 5587-5595, doi:10.1029/JD095iD05p05587, 1990.

Rothman, L., Rinsland, C., Goldman, A., Massie, S. T., and Edwards, D. P.: The HITRAN molecular spectroscopic database and HAWKS (HITRAN atmospheric workstation): 1996 edition, J. Quant. Spectrosc. Ra., 60, 665-710, doi:10.1016/S00224073(98)00078-8, 1998.

Steinbrecht, W., Claude, H., Schönenborn, F., McDermid, I., Leblanc, T., Godin, S., Song, T., Swart, D., Meijer, Y., Bodeker, G., Connor, B., Kämpfer, N., Hocke, H., Calisesi, Y., Schneider, N., Noe, J., Parrish, A., Boyd, I., Brühl, C., Steil, B., Giorgetta, M., Manzini, E., Thomasson, L., Zawodny, J., McCormick, M., Russel III, J., Bhartia, P., Stolarski, R., and Hollandsworth-Frith, S.: Long-term evolution of upper stratospheric ozone at selected stations of the Network for the De- 
tection of Stratospheric Change (NDSC), J. Geophys. Res., 111, D10308, doi:10.1029/2005JD006454, 2006.

Steinbrecht, W., McGee, T. J., Twigg, L. W., Claude, H., Schönenborn, F., Sumnicht, G. K., and Silbert, D.: Intercomparison of stratospheric ozone and temperature profiles during the October 2005 Hohenpeißenberg Ozone Profiling Experiment (HOPE), Atmos. Meas. Tech., 2, 125-145, doi:10.5194/amt-2-125-2009, 2009.

Stiller, G. P., von Clarmann, T., Haenel, F., Funke, B., Glatthor, N., Grabowski, U., Kellmann, S., Kiefer, M., Linden, A., Lossow, S., and López-Puertas, M.: Observed temporal evolution of global mean age of stratospheric air for the 2002 to 2010 period, Atmos. Chem. Phys., 12, 3311-3331, doi:10.5194/acp-12-33112012, 2012.

Studer, S., Hocke, K., Pastel, M., Godin-Beekmann, S., and Kämpfer, N.: Intercomparison of stratospheric ozone profiles for the assessment of the upgraded GROMOS radiometer at Bern, Atmos. Meas. Tech. Discuss., 6, 6097-6146, doi:10.5194/amtd6-6097-2013, 2013.

Studer, S., Hocke, K., Schanz, A., Schmidt, H., and Kämpfer, N.: A climatology of the diurnal variations in stratospheric and mesospheric ozone over Bern, Switzerland, Atmos. Chem. Phys., 14, 5905-5919, doi:10.5194/acp-14-5905-2014, 2014.

Tiao, G. C., Reinsel, G. C., Xu, D., Pedrick, J. H., Zhu, X., Miller, A. J., DeLuisi, J. J., Mateer, C. L., and Wuebbles, D. J.: Effects of autocorrelation and temporal sampling schemes on estimates of trend and spatial correlation, J. Geophys. Res., 95, 20507-20517, doi:10.1029/JD095iD12p20507, 1990.

Tummon, F., Hassler, B., Harris, N. R. P., Staehelin, J., Steinbrecht, W., Anderson, J., Bodeker, G. E., Bourassa, A., Davis, S. M., Degenstein, D., Frith, S. M., Froidevaux, L., Kyrölä, E., Laine, M., Long, C., Penckwitt, A. A., Sioris, C. E., Rosenlof, K. H., Roth, C., Wang, H.-J., and Wild, J.: Intercomparison of vertically resolved merged satellite ozone data sets: interannual variability and long-term trends, Atmos. Chem. Phys., 15, 3021-3043, doi:10.5194/acp-15-3021-2015, 2015. van Gijsel, J. A. E., Swart, D. P. J., Baray, J.-L., Bencherif, H., Claude, H., Fehr, T., Godin-Beekmann, S., Hansen, G. H., Keckhut, P., Leblanc, T., McDermid, I. S., Meijer, Y. J., Nakane, H., Quel, E. J., Stebel, K., Steinbrecht, W., Strawbridge, K. B., Tatarov, B. I., and Wolfram, E. A.: GOMOS ozone profile validation using ground-based and balloon sonde measurements, Atmos. Chem. Phys., 10, 10473-10488, doi:10.5194/acp10-10473-2010, 2010.

Vigouroux, C., De Mazière, M., Demoulin, P., Servais, C., Hase, F., Blumenstock, T., Kramer, I., Schneider, M., Mellqvist, J., Strandberg, A., Velazco, V., Notholt, J., Sussmann, R., Stremme, W., Rockmann, A., Gardiner, T., Coleman, M., and Woods, P.: Evaluation of tropospheric and stratospheric ozone trends over Western Europe from ground-based FTIR network observations, Atmos. Chem. Phys., 8, 6865-6886, doi:10.5194/acp-8-6865-2008, 2008.

Vigouroux, C., Blumenstock, T., Coffey, M., Errera, Q., García, O., Jones, N. B., Hannigan, J. W., Hase, F., Liley, B., Mahieu, E., Mellqvist, J., Notholt, J., Palm, M., Persson, G., Schneider, M., Servais, C., Smale, D., Thölix, L., and De Mazière, M.: Trends of ozone total columns and vertical distribution from FTIR observations at eight NDACC stations around the globe, Atmos. Chem. Phys., 15, 2915-2933, doi:10.5194/acp-15-2915-2015, 2015.

von Clarmann, T., Stiller, G., Grabowski, U., Eckert, E., and Orphal, J.: Technical Note: Trend estimation from irregularly sampled, correlated data, Atmos. Chem. Phys., 10, 6737-6747, doi:10.5194/acp-10-6737-2010, 2010.

WMO (World Meteorological Organization): Scientific Assessment of Ozone Depletion: 2010, Global Ozone Research and Monitoring Project-Report No. 52, 516 pp., Geneva, Switzerland, 2011.

WMO (World Meteorological Organization): Scientific Assessment of Ozone Depletion: 2014, Global Ozone Research and Monitoring Project - Report No. 55, 416 pp., Geneva, Switzerland, 2014. 